\title{
Experimental study of vortex-induced vibrations of a cylinder near a rigid plane boundary in steady flow
}

\author{
Bing Yang • Fuping Gao • Dong-Sheng Jeng • \\ Yingxiang Wu
}

Received: 13 March 2008 / Revised: 23 October 2008 / Accepted: 23 October 2008 / Published online: 10 January 2009

(C) The Chinese Society of Theoretical and Applied Mechanics and Springer-Verlag GmbH 2009

\begin{abstract}
In this study, the vortex-induced vibrations of a cylinder near a rigid plane boundary in a steady flow are studied experimentally. The phenomenon of vortex-induced vibrations of the cylinder near the rigid plane boundary is reproduced in the flume. The vortex shedding frequency and mode are also measured by the methods of hot film velocimeter and hydrogen bubbles. A parametric study is carried out to investigate the influences of reduced velocity, gap-to-diameter ratio, stability parameter and mass ratio on the amplitude and frequency responses of the cylinder. Experimental results indicate: (1) the Strouhal number $(S t)$ is around 0.2 for the stationary cylinder near a plane boundary in the sub-critical flow regime; (2) with increasing gap-to-diameter ratio $\left(e_{0} / D\right)$, the amplitude ratio $(A / D)$ gets larger but frequency ratio $\left(f / f_{n}\right)$ has a slight variation for the case of larger values of $e_{0} / D\left(e_{0} / D>0.66\right.$ in this study); (3) there is a clear difference of amplitude and frequency responses of the cylinder between the larger gap-to-diameter ratios $\left(e_{0} / D>0.66\right)$ and the smaller ones $\left(e_{0} / D<0.3\right)$; (4) the vibration of the cylinder is easier to occur and the range of vibration in terms of $V_{r}$ number becomes more extensive with decrease of the stability parameter, but the frequency response is affected slightly by the stability parameter; (5) with decreasing mass
\end{abstract}

This project was supported by the National Natural Science Foundation of China (50509022, 10532070), Knowledge Innovation Program of the Chinese Academy of Sciences (KJCX2-YW-L02).

B. Yang $(\varangle) \cdot$ F. Gao $\cdot$ Y. Wu

Institute of Mechanics, Chinese Academy of Sciences, 100190 Beijing, China

e-mail: byang@imech.ac.cn

D.-S. Jeng

Division of Civil Engineering, School of Engineering, Physics and Mathematics, University of Dundee,

Dundee DD1 4HN, Scotland, UK ratio, the width of the lock-in ranges in terms of $V_{r}$ and the frequency ratio $\left(f / f_{n}\right)$ become larger.

Keywords Vortex-induced vibration - Cylinder near a plane boundary $\cdot$ Steady flow $\cdot$ Vortex shedding

\section{Introduction}

For a bluff body exposed to steady flow, there exist vortices being shed alternately from either side of the body in the downstream, when Reynolds number is larger than certain value (e.g., 40). A periodic force is exerted on the bluff body due to vortex shedding, whose component in the transverse direction (i.e., lift force) has the same frequency as the vortex shedding, while the component in the in-line direction has a frequency equal to twice the shedding frequency [1]. In many situations, the forces exerted on the body can cause vortex-induced vibrations (VIVs), which have been observed in many engineering fields, such as the vibrations of heat exchanger tubes in steady flow, submarine pipeline installed on seabed in ocean current, bridges and chimneys in civil engineering under action of wind, and so on. Vortex-induced vibration has been recognized as one of the dominating causes for the fatigue damage to the structures. Thus, an appropriate analysis of the dynamic responses of structures subjected to VIV is particularly important for practical engineers involving in the design of marine structures.

There have existed many investigations on dynamic responses of a cylinder undergoing vortex-induced vibrations since the last two decades [2-9]. Among these, Feng [10] conducted the well-known experiments on cross-flow vibrations of a circular cylinder in air flow. In his study, the typical lock-in phenomenon was presented. Anand [11] found that 
the vibration frequency of the cylinder placed in the water is different from the natural frequency of the cylinder in the lock-in range, but it increases monotonously with reduced velocity. In general, when a cylinder is exposed to air flow, only two amplitude response branches exist, i.e., initial branch and lower branch $[10,12]$. On the other hand, when the cylinder is placed in water flow, the third branch (i.e., upper branch) is observed [13-16].

Both Khalak and Williamson [17] and Brika and Laneville [12], based on their flow-visualizations in wall-free vibration tests, concluded that the jump of vibration amplitude from the initial branch to the lower branch corresponds to a mode change from $2 \mathrm{~S}$ to $2 \mathrm{P}$. Herein, $2 \mathrm{~S}$ indicates two single vortices formed per cycle and $2 \mathrm{P}$ means two pairs of vortices formed per cycle [18]. With the same definition of the upper amplitude branch in Khalak and Williamson [13-15,17], Govardhan and Williamson [16] provided clear evidence of the vortex formation modes corresponding to the upper amplitude branch by use of the digital particle image velocimetry (DPIV) technique.

A combined parameter $\left(m^{*} \zeta\right)$ has been commonly used to investigate the maximum amplitude response of vortexinduced vibration in the literatures [7,19-22]. Herein, $m^{*}$ is the mass ratio which represents the ratio of cylinder mass per meter to fluid mass whose volume is the same as that occupied by the cylinder per meter, and $\zeta$ is the structural damping factor of a cylinder. However, it has been argued that the maximum response amplitude is not controlled only by a combined parameter $m^{*} \zeta$, but also by $m^{*}$ and $\zeta$ independently [2,23-25].

In some situations, a cylinder will be installed near a plane boundary (e.g., a submarine pipeline placed on the seabed), and the flow field around the cylinder will be affected due to the existence of the boundary. When the initial gap between the cylinder and the plane boundary is small, the vortex shedding at the downstream side of the cylinder will be suppressed [26]. While the initial gap is larger than about $0.3 \mathrm{D}$, the vortex shedding frequency is affected slightly by the boundary [27-30]. It has been reported that the maximum response amplitude takes place at the larger reduced velocity $V_{r}\left(V_{r}=U /\left(f_{n} D\right), U\right.$ is the flow velocity, $f_{n}$ is the natural frequency of the cylinder, $D$ is the cylinder diameter) due to the influence of the wall [31,32]. Jacobsen et al. [33] studied the amplitude response of a cylinder suspended in a spring system with gap-to-diameter ratios equal to 0 , 0.5 and 1 . Based on the work by Tsahalis and Jones $[31,32]$ and Jacobsen et al.[33], Fredsoe et al. [34] investigated the cross-flow vibration of cylinders near a wall, and their study indicated that the transverse vibration frequency is close to the frequency of vortex shedding from a stationary cylinder, when reduced velocity is less than the value of 3 and the initial gap between the cylinder and the wall $\left(e_{0}\right)$ is more than $0.3 D$; For the case of $3<V_{r}<8$ and $0<e_{0}<1 D$ the transverse vibrating frequency is noticeably larger than the frequency of vortex shedding from a stationary cylinder. Raven and Stuart [36] carried out the full-scale tests upon the vortex-induced vibration of the pipeline, and they indicated that the critical $V_{r}$ number for the occurrence of vibration would be affected by the initial gap.

From the aforementioned paragraphs, most of investigations have considered the wall-free cylinder case. The cylinders near a plane wall are paid attention by fewer researchers. To enrich the research upon the vortex-induced vibration of the cylinder near a wall, some work need to be done further.

In this study the dynamic responses of a cross-flow vortex-induced vibration of the cylinder near a rigid plane boundary in steady water flow are investigated experimentally. The typical characteristics of vortex-induced vibration will be described and vortex-shedding frequency will be measured. Then, the influences of such parameters as initial gap between the cylinder and the boundary, the mass of the cylinder and the structural damping of the cylinder on the amplitude and frequency responses will be examined.

\section{Experimental details}

A special apparatus is designed and constructed for the present experiments, which operates in conjunction with a flume, as depicted in Fig. 1. The flume is $0.5 \mathrm{~m}$ wide, $0.6 \mathrm{~m}$ deep and $19 \mathrm{~m}$ long, which can generate the steady flow with velocity up to approximately $0.6 \mathrm{~m} / \mathrm{s}$. The cylinder is installed at the supporting frame by two connecting poles. The details about the apparatus can be found in the work by Gao et al. [35].

In this study, two cylinders with diameters of 0.032 and $0.05 \mathrm{~m}$ are used. The cylinder surface is smooth, i.e., $\kappa \approx 0$, and the water depth is maintained at $0.3 \mathrm{~m}$. A laser displacement transducer with a resolution of $0.3 \mathrm{~mm}$ is employed for the non-contact measurement of the vertical displacements of the cylinder (see Fig. 1). Because the displacement of sliding pole is consistent with the cylinder, the displacement of the cylinder can be obtained by measuring the displacement of sliding pole. The flow velocity is measured by micro-propeller current meter, and the values of $f_{n}$ and $\zeta$ are determined by performing free-decay tests in still water. Some of typical curves for free-decay tests are shown in Fig. 2.

\section{Results and discussion}

In this study, some dimensionless parameters will be used to illustrate the experimental results. Although they have been described in some literatures $[8,17,35]$, they are listed here for convenience, as shown in Table 1. 


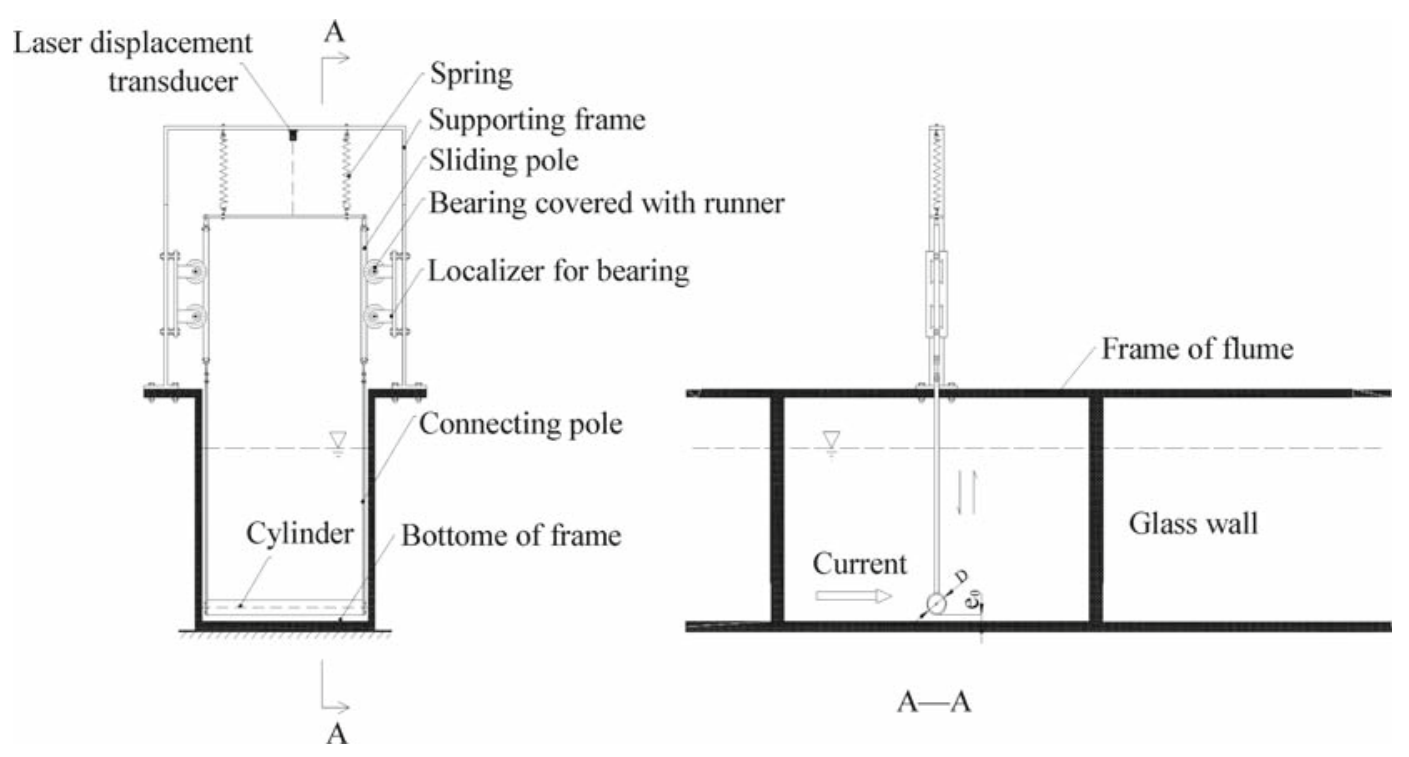

Fig. 1 Schematic of experimental setup
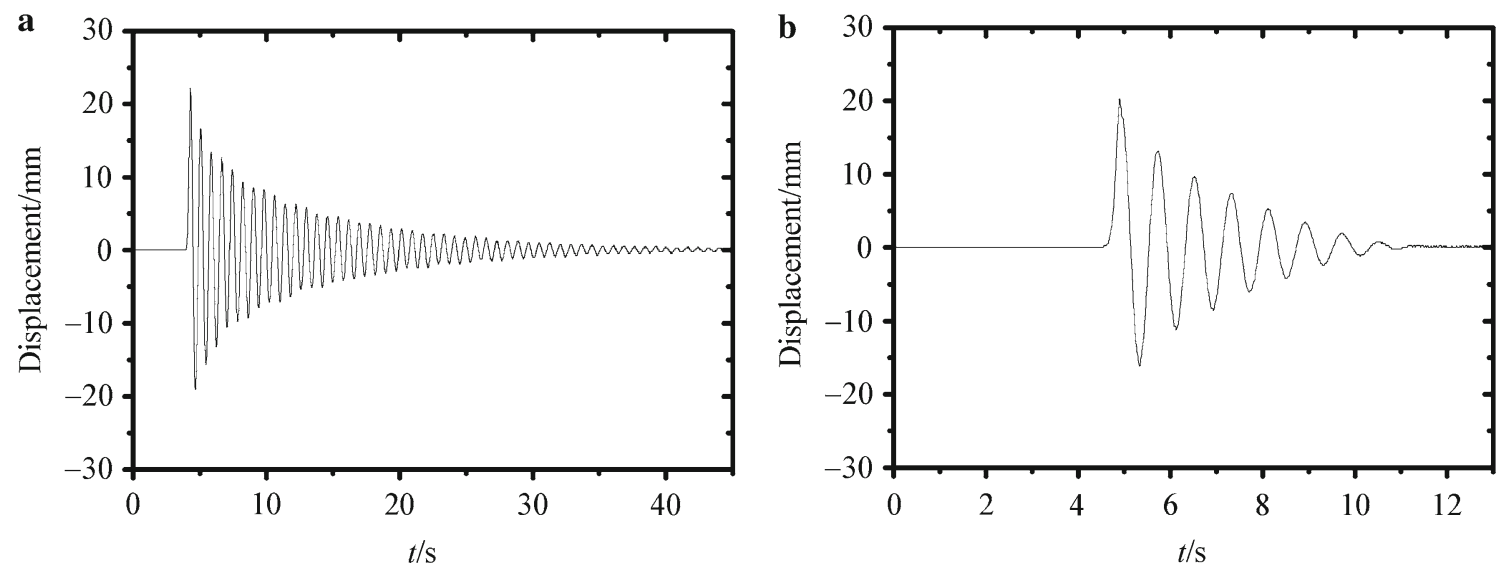

Fig. 2 Typical curves of free-decay tests. a $\zeta=0.0152, \mathbf{b} \zeta=0.0695$

Table 1 Dimensionless parameters relevant to dynamic interaction between flow, cylinder and plane boundary

\begin{tabular}{lll}
\hline Name & Symbols & Definition \\
\hline Mass ratio & $m^{*}$ & $(4 m) /\left(\pi \rho D^{2}\right)$ \\
Reduced velocity & $V_{r}$ & $U /\left(f_{n} D\right)$ \\
Relative roughness & $\kappa$ & $k_{S} / D$ \\
Stability parameter & $K_{s}$ & $\left(4\left(m+m_{a}\right) \zeta\right) /\left(\pi \rho D^{2}\right)$ \\
Reynolds number & $R e$ & $(U D) / v$ \\
Gap-to-diameter ratio & $e_{0} / D$ & $e_{0} / D$ \\
\hline
\end{tabular}

3.1 The typical phenomenon of vortex-induced vibration of the cylinder near a rigid plane boundary

The typical time traces of vibration displacement of the cylinder with larger value of initial gap-to-diameter ratio are shown in Fig. 3. It is noted that the value of initial gapto-diameter ratio $\left(e_{0} / D\right)$ is 4.69 , the mass ratio $m^{*}=3.87$, the damping factor $\zeta=0.0152$, the natural frequency $f_{n}=$ $1.27 \mathrm{~Hz}$, and $D=0.032 \mathrm{~m}$. For the case of $e_{0} / D=4.69$, the cylinder does not collide with the plane boundary during the course of vibration, and the curves of vibration displacement of the cylinder are symmetric. It is observed in Fig. 3 that the vibration amplitude of the cylinder undergoes the process of increasing-maximum-decreasing variation with increasing flow velocity. When the vibration amplitude is small, i.e., at the initial and final stages of vibration (e.g., $U=0.114,0.158$, and $0.445 \mathrm{~m} / \mathrm{s}$ ), the vibrating frequency of the cylinder is very close to the natural frequency of the cylinder. Moreover, the vibration frequency of the cylinder increases slowly with flow velocity except for the range of small amplitudes (i.e., at the initial and final stages of vibration). 
a

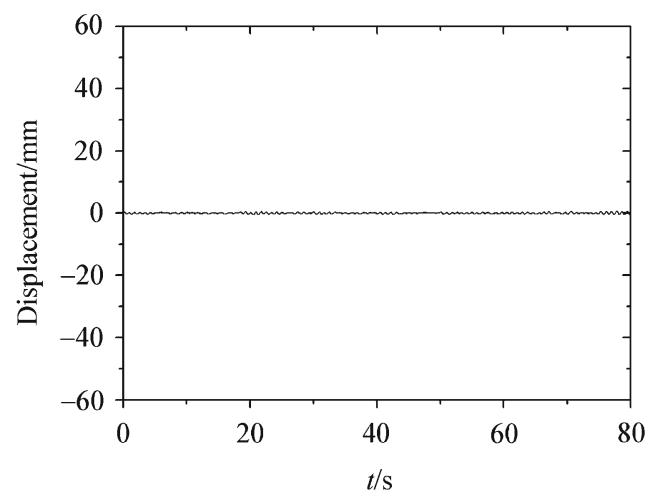

b

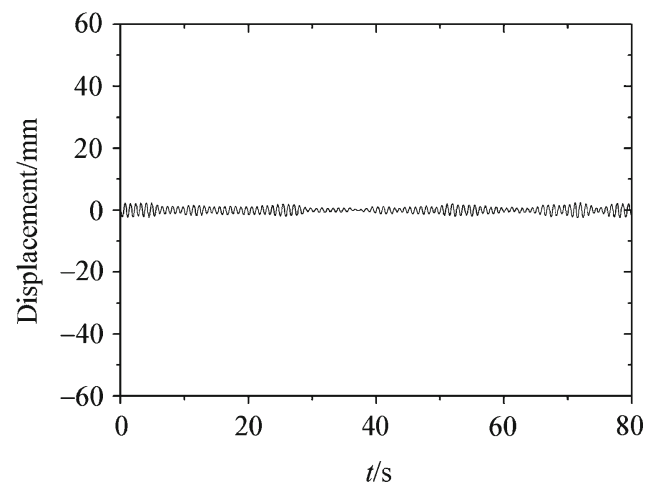

c

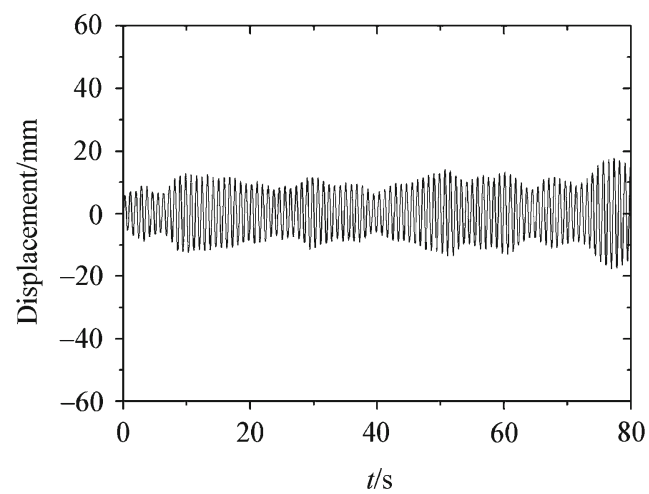

d

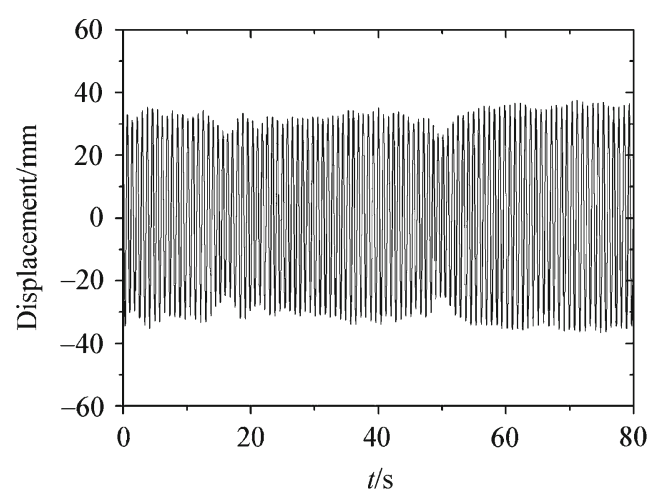

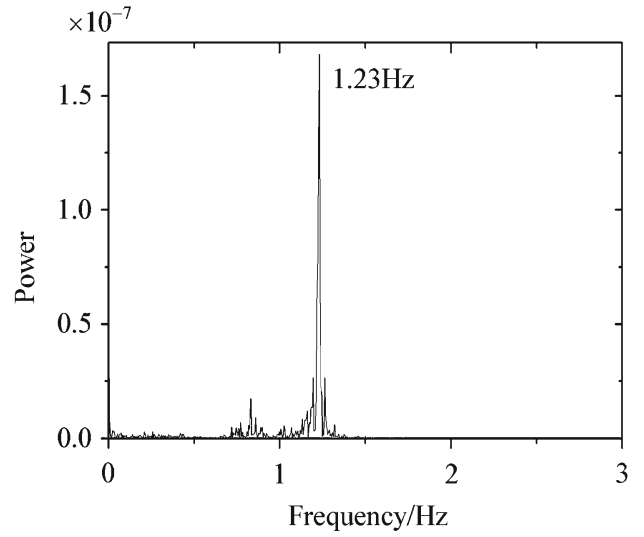
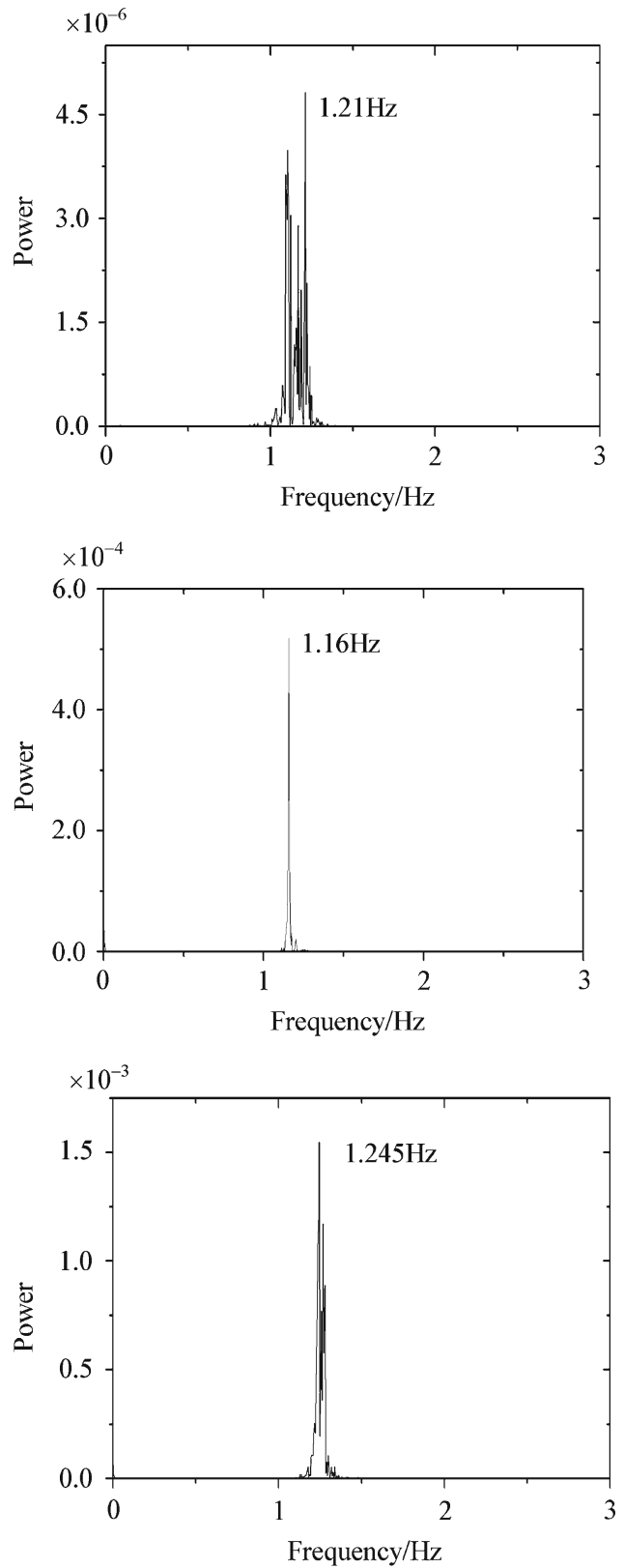

Fig. 3 Time traces of displacement for a cylinder with $e_{0} / D=4.69$. a $U=0.114 \mathrm{~m} / \mathrm{s} ; \mathbf{b} U=0.158 \mathrm{~m} / \mathrm{s} ; \mathbf{c} U=0.190 \mathrm{~m} / \mathrm{s} ; \mathbf{d} U=0.258 \mathrm{~m} / \mathrm{s}$; e $U=0.322 \mathrm{~m} / \mathrm{s} ; \mathbf{f} U=0.396 \mathrm{~m} / \mathrm{s} ; \mathbf{g} U=0.445 \mathrm{~m} / \mathrm{s}$ 
e

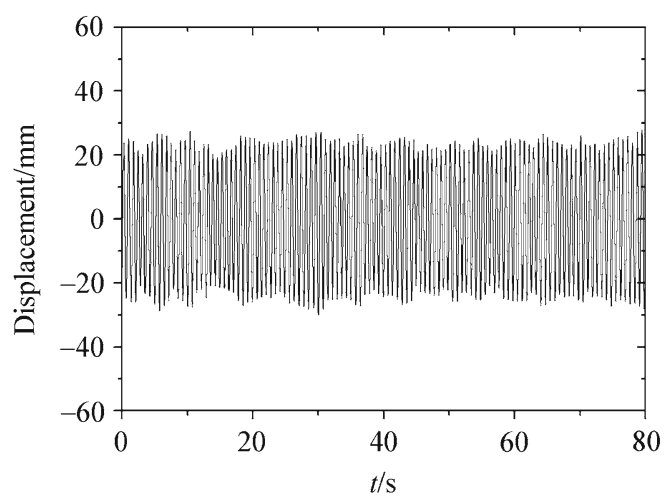

f

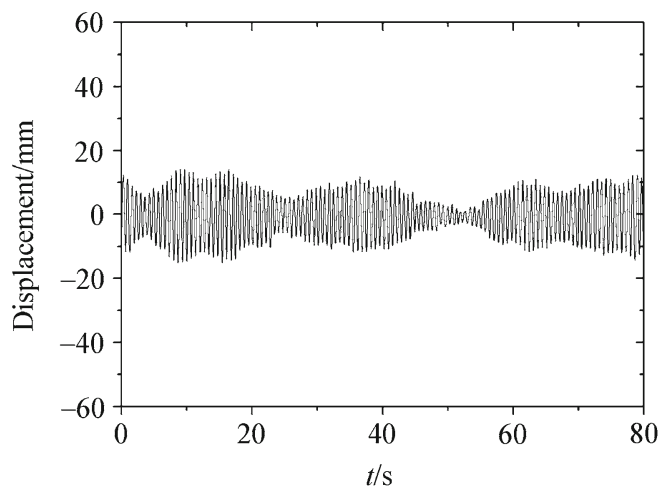

g

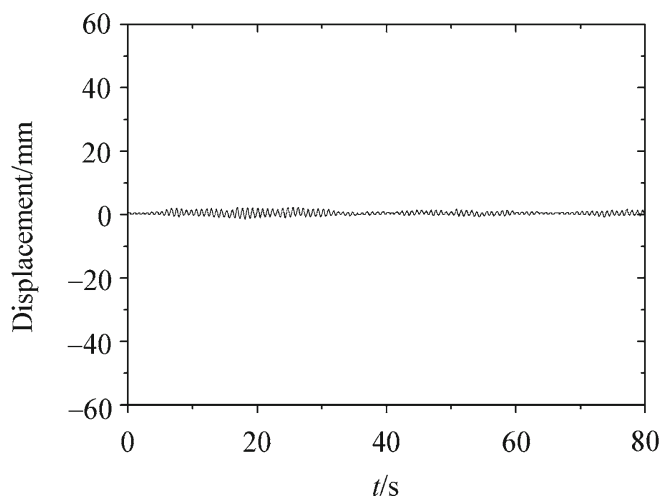

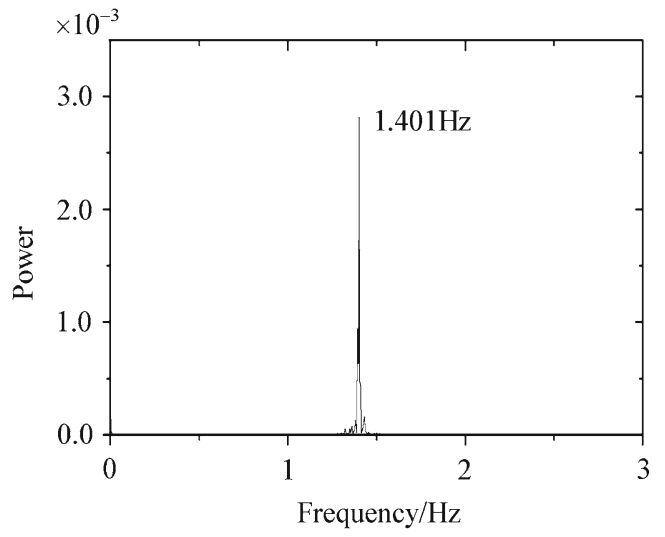
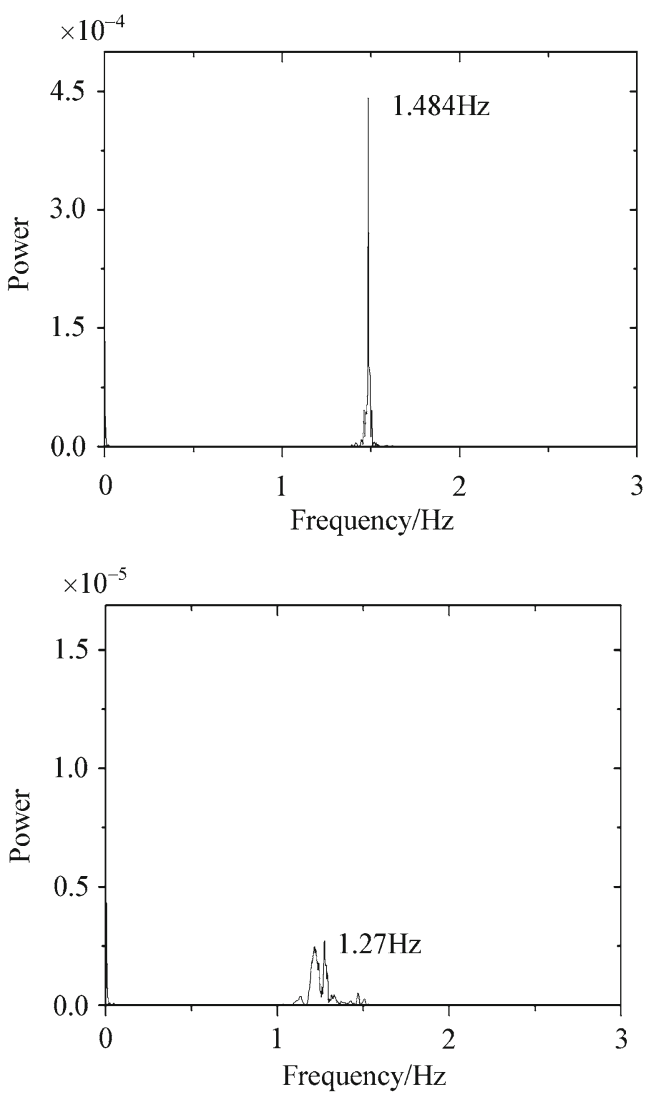

Fig. 3 continued

We re-arrange the results presented in Fig. 3 with the dimensionless quantities, $A / D, f / f_{n}, V_{r}$, as shown in Fig. 4, where $A$ is the mean amplitude of vibration, $f$ is the vibration frequency of the cylinder. The variation of shedding frequency of wake vortices from the static wall-free cylinder with reduced velocity $\left(V_{r}\right)$, i.e., Strouhal line, is plotted in Fig. 4b, which is defined as:

$\frac{f_{v}}{f_{n}}=\frac{f_{v} D}{U} \frac{U}{f_{n} D}=S t V_{r}$,

in which $f_{v}$ is the wake vortices shedding frequency around the cylinder, $S t$ is the Strouhal number. The value of $S t$ mainly depends on the Reynolds number $(R e)$ and the relative roughness of the cylinder's surface [8]. As reported in Achenbach [37], the Strouhal number is around 0.2 for the sub-critical flow regime (i.e., $300<R e<3 \times 10^{5}$ ), regardless of the value of relative roughness. The value of Reynolds number in this study is in the range of sub-critical flow regime, so the value of $S t$ is set as 0.2 for the Strouhal line in this study.

Figure $4 \mathrm{a}$ shows that the cylinder starts to vibrate at about $V_{r}=2.6$. When $V_{r}$ number increases to the value of 3.9, the amplitude of vibration $(A)$ reaches about $0.09 D$. When $V_{r}=$ 4.3 , the amplitude $(A)$ reaches about $0.23 D$. However, when 

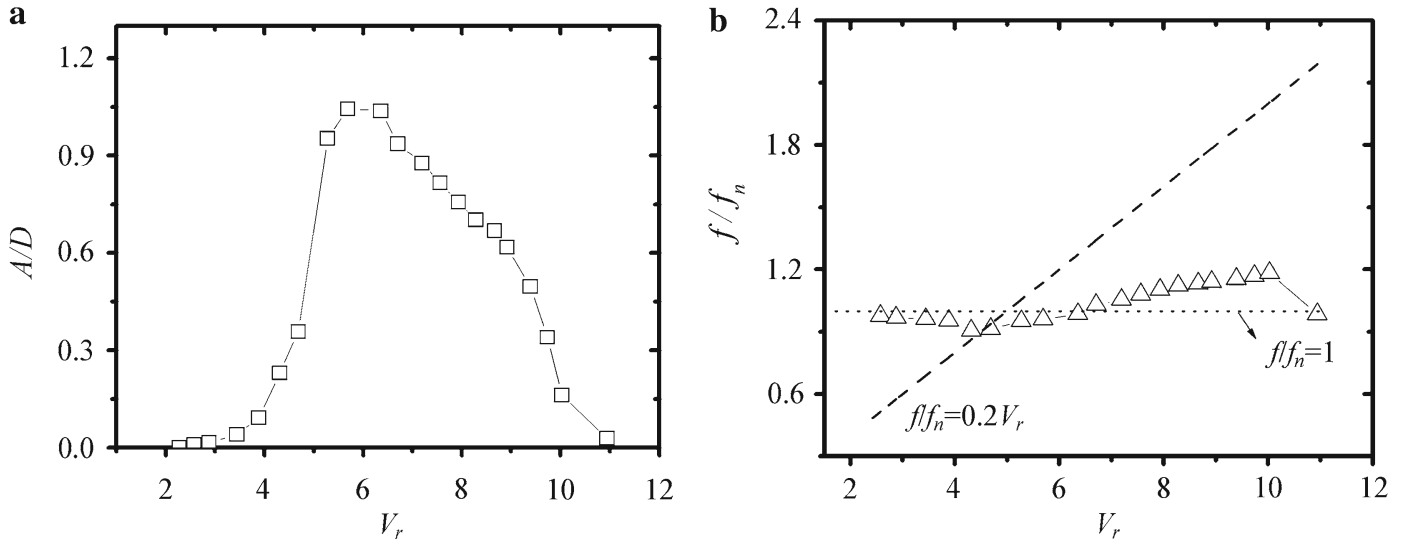

Fig. 4 The response of amplitude and frequency for a cylinder undergoing vortex-induced vibration (dimensionless form) ( $A$ : the mean amplitude; $\left.D=0.032 \mathrm{~m}, m=3.107 \mathrm{~kg} / \mathrm{m}, e_{0}=150 \mathrm{~mm}, f_{n}=1.27 \mathrm{~Hz}, \zeta=0.0152\right)$. a Amplitude response; $\mathbf{b}$ frequency response
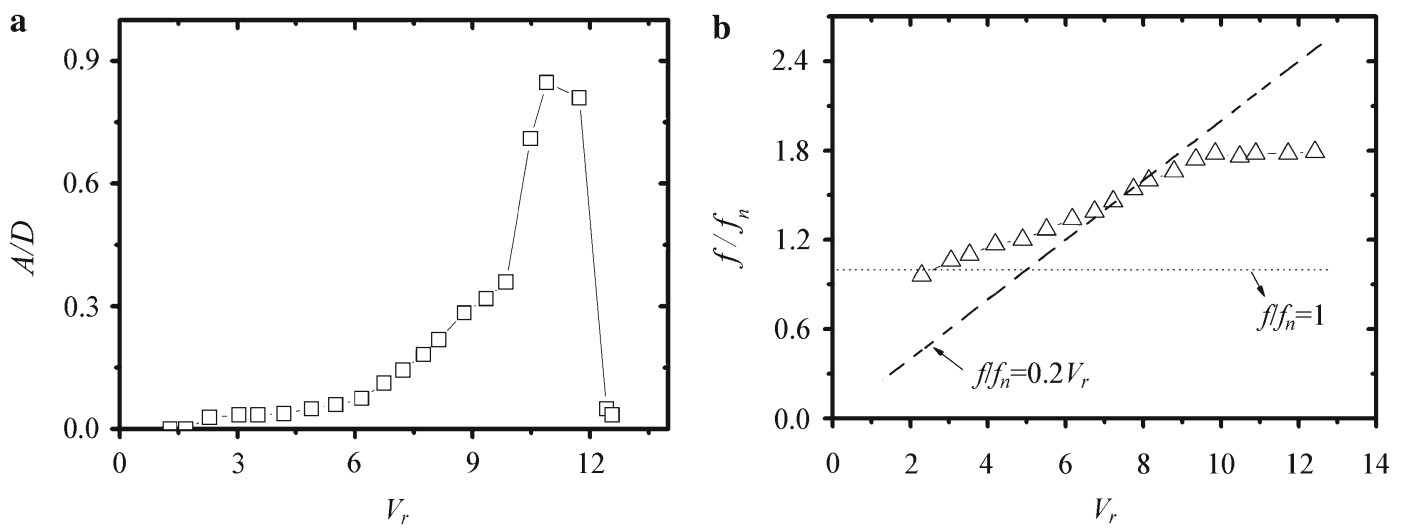

Fig. 5 The response of amplitude and frequency for a cylinder undergoing vortex-induced vibration (dimensionless form) $(D=0.032 \mathrm{~m}$, $\left.e_{0} / D=0.06, m^{*}=3.87, K_{s}=0.0741\right)$. a Amplitude response; $\mathbf{b}$ frequency response

$V_{r}$ number changes from 4.7 to 5.3 , the amplitude of vibration undergoes a jump from $0.36 D$ to $0.95 D$. According to Strouhal's law, the vortex shedding frequency is $1.19 \mathrm{~Hz}$ which is close to the natural frequency of the cylinder $\left(f_{n}=\right.$ $1.27 \mathrm{~Hz}$ ) at $V_{r}=4.7$, so the strong coupling interaction between the flow and the cylinder results in the jump of the amplitude. The maximum amplitude with a value of $1.04 \mathrm{D}$ occurs at about $V_{r}=5.7$, and then the amplitude of vibration decreases continuously with $V_{r}$ number without a distinct jump. Finally, the vibrating amplitude $(A)$ decreases to $0.028 D$ at $V_{r}=10.9$ in which the coupling interaction between the flow and the cylinder is weak.

As for the frequency of vibrations, when $V_{r}$ is less than 3.9 and $A / D<0.1$, the vibration frequency of the cylinder is close to the natural frequency of the cylinder. When $V_{r}=4.3$ and $A / D=0.23$, the vibration frequency of the cylinder clearly begins to deviate from the natural frequency. After that, the vibration frequency increases slowly with $V_{r}$ number. At the end of vibration, the vibration frequency of the cylinder is close to the natural frequency again, as shown in Fig. 4b.
Figure 5 illustrates the non-dimensional amplitude and frequency responses for the case of $e_{0} / D=0.06$. It is shown in the figure that there exists distinct differences between the case of $e_{0} / D=4.69$ and $e_{0} / D=0.06$. The maximum vibration amplitude with a value of $0.85 \mathrm{D}$ occurs at the larger value of $V_{r}$ number (i.e., $V_{r}=10.8$ ), and the vibration frequency is much larger than that for the case of $e_{0} / D=4.69$ under the same conditions. The influences of gap-to-diameter ratio on the response of the cylinder will be discussed further in next section.

\subsection{Characteristic of lee-wake vortices shed from the cylinder}

In this study, the hot film velocimeter was used to measure the pulse velocity of the fluid in the wake flow of the cylinder, and the frequency of lee-wake vortices shed from the cylinder can be determined by Fourier analysis. The typical signal of hot film and the corresponding frequency spectrum for the case of stationary cylinder with $e_{0} / D=1.50$ at the velocity of $U=0.084 \mathrm{~m} / \mathrm{s}$ are shown in Fig. 6. The figure 

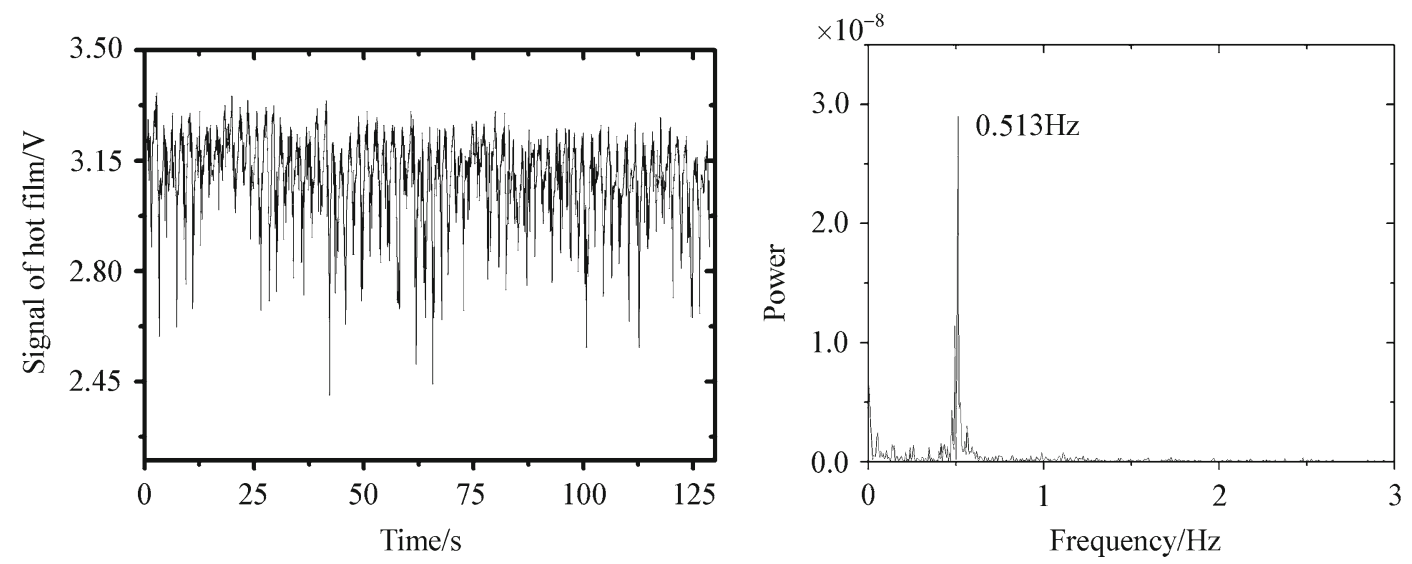

Fig. 6 Typical signal of hot film and corresponding power spectrum $\left(D=32 \mathrm{~mm}, e_{0} / D=1.50, U=0.084 \mathrm{~m} / \mathrm{s}\right)$

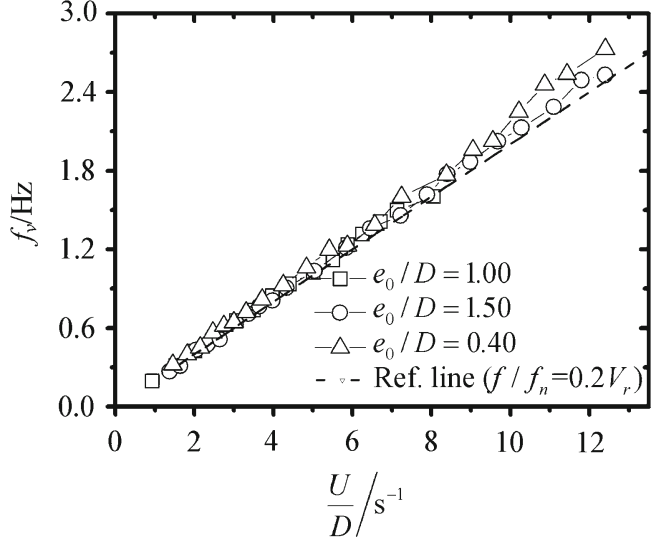

Fig. 7 Shedding frequency for wake vortices from the fixed cylinder close to a plane boundary versus $U / D(R e=1.4 \times 103-1.9 \times 104)$

clearly indicates that the hot film is a useful means to measure the shedding frequency of wake vortices. The variation of the shedding frequency of lee-wake vortices from the stationary cylinder $\left(f_{v}\right)$ with the parameter $U / D$ under the condition of different gap-to-diameter ratios is plotted in Fig. 7. It is observed in Fig. 7 that the vortex shedding frequency $\left(f_{v}\right)$ varies almost linearly with the parameter $U / D$. It is noted that the value of Strouhal number $(S t)$ is the slope of the curves in Fig. 7. The values of $S t$ for three gap-to-diameter ratios, i.e., $e_{0} / D=0.40,1.00,1.50$, are $0.22,0.21$ and 0.205 , respectively. This means that the Strouhal number $(S t)$ is still around 0.2 for the cylinder near a plane boundary in the subcritical flow regime, which is consistent with the conclusions by Bearman et al. [26] and Grass [27].

Figure 8 shows the signal of hot film and the corresponding power spectrum for the case of stationary cylinder with $e_{0} / D=0$ and 0.20 . The power spectrum shows that it is difficult to distinguish the vortex shedding frequency for the case of very small gap-to-diameter ratio (e.g., $e_{0} / D=$ 0.20 ), which indicates that the behavior of lee-wake vortices shed from the stationary cylinder is suppressed by the plane boundary. The results reported by Bearman et al. [26] also showed that the vortex shedding from the cylinder was affected heavily by the plane wall for the case of $e_{0} / D<$ 0.30 . In sum, when the gap between the cylinder and the plane boundary decreases to a certain value, the vortex shedding will be suppressed by the rigid wall and the phenomenon of vortex shedding from the stationary cylinder will disappear.

For the case of the cylinder undergoing vortex-induced vibration, the variation of the shedding frequency of lee-wake vortices with $V_{r}$ number is illustrated in Fig. 9. It is observed in the figure that the vortex shedding frequency follows the Strouhal's law at the small $V_{r}$ number (i.e., the cylinder is stationary), and it starts to deviate from the Strouhal's law but varies along the same law with the vibrating frequency of the cylinder at the larger $V_{r}$ number (i.e., the cylinder is experiencing VIV), which is the well-known lock-in phenomenon. The above results consist with those for wall-free cases by King et al. [38] and Anand [11].

\subsection{Lee-wake flow around the cylinder}

In this section, the visualization of the flow around the static cylinder with the method of hydrogen bubble is conducted (see Fig. 10). It is indicated from Fig. 10 that the vortex is suppressed when the cylinder is very close to the boundary. Therefore, for the case of $e_{0} / D=0.20$ in Fig. 10a, it is difficult to identify the vortex in the wake flow, but in Fig. 10b with larger gap-to-diameter ratio of $e_{0} / D=1.00$, a vortex pair exists clearly in the wake flow.

Figure 11 presents the flow visualization of wake flow around a cylinder undergoing vortex-induced vibration under the condition of $A / D=0.18, V_{r}=3.6$. As shown in Fig. 11, the vortex sheds alternatively from the top and bottom surfaces of the cylinder in a period of vibration, and the directions of the vortex shedding from the top and bottom are opposite. Therefore, the vortex shedding mode at the initial 
a

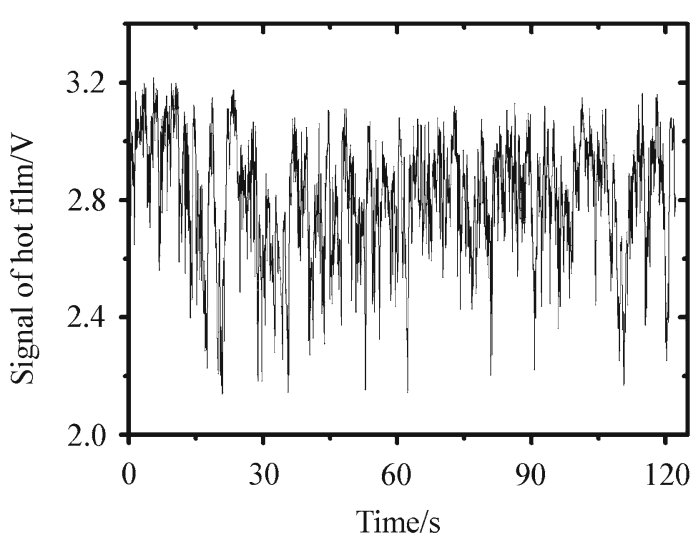

b

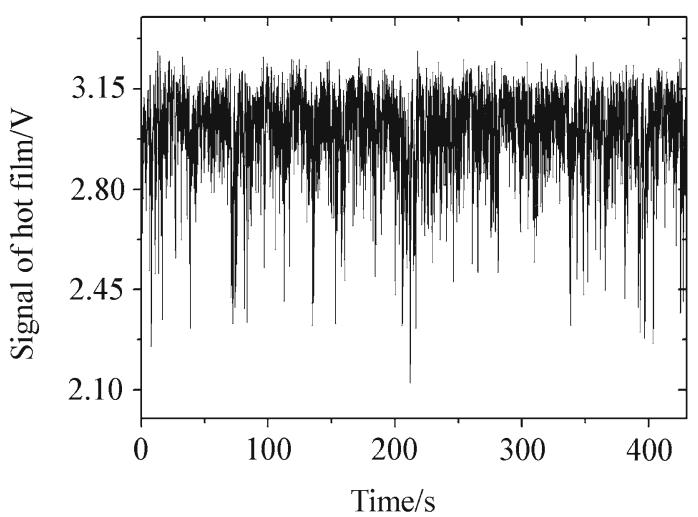

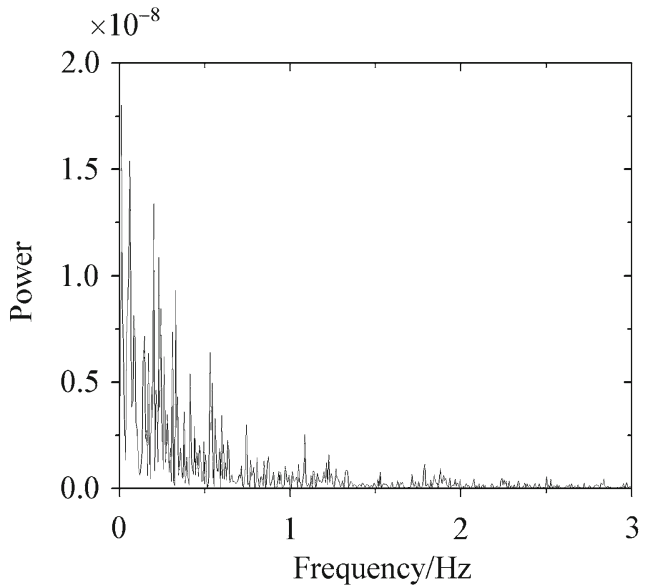

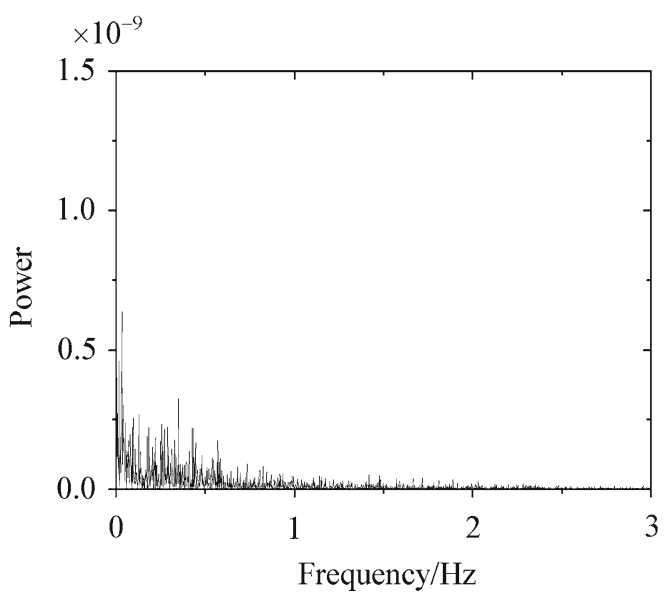

Fig. 8 Typical signal of hot film in the wake flow of the very close-wall cylinder with $e_{0} / D=0.20$ and corresponding power spectrum. a $D=32 \mathrm{~mm}, e_{0} / D=0, U=0.084 \mathrm{~m} / \mathrm{s} ; \mathbf{b} D=32 \mathrm{~mm}, e_{0} / D=0.20, U=0.175 \mathrm{~m} / \mathrm{s}$

stage with $V_{r}=3.6$ and $A / D=0.18$ is $2 \mathrm{~S}$ mode which is defined by Williamson and Roshko [18]. Govardhan and Williamson [16] investigated the shedding modes of wake vortices around the wall-free cylinder undergoing transverse vortex-induced vibration, whose results are consistent with those in this study.

\subsection{Effect of several dimensionless parameters on the response of the cylinder}

\subsubsection{Effect of $V_{r}$ number}

$V_{r}$ number is a dimensionless parameter that consists of flow velocity $U$, the natural frequency of the cylinder $f_{n}$ and cylinder's diameter $D$. The physical meaning of $V_{r}$ number can be explained as the ratio of fluid force acting on the cylinder and the elastic restoring force of the cylinder. For the vortexinduced vibration of the cylinder, $V_{r}$ number is an important parameter. Figures 4 and 5 clearly indicate that when other dimensionless parameters are fixed, the $V_{r}$ number dominates the process of vortex-induced vibration of the cylinder, i.e., the occurrence, development and disappearance of the vibration are determined by $V_{r}$ number.

\subsubsection{Effect of gap-to-diameter ratio $\left(e_{0} / D\right)$}

Figure 12 presents the frequency and amplitude responses of the cylinder with various gap-to-diameter ratios. As shown in Fig. 12a, when the value of gap-to-diameter ratio is larger $\left(e_{0} / D>0.66\right.$ in this study), the dimensionless maximum vibration amplitude of the cylinder $(A / D)$ increases with the increasing gap-to-diameter ratio. However, the dimensionless vibration frequency of the cylinder $\left(f / f_{n}\right)$ has slight variation with the increasing gap-to-diameter ratio in the case above, as indicated in Fig. 12b. It can also be observed in Fig. 12a that the dimensionless amplitude of vibration for the cases of $e_{0} / D=0.06$ and 0.30 increases slowly at the initial stage (i.e., at small $V_{r}$ number) and decreases quickly at the last stage (i.e., at large $V_{r}$ number). Moreover, the $V_{r}$ number at which the dimensionless maximum amplitude occurs for the gap-to-diameter ratio $e_{0} / D=0.06$ is larger than that for $e_{0} / D=0.30$, which is consistent with the conclusions 

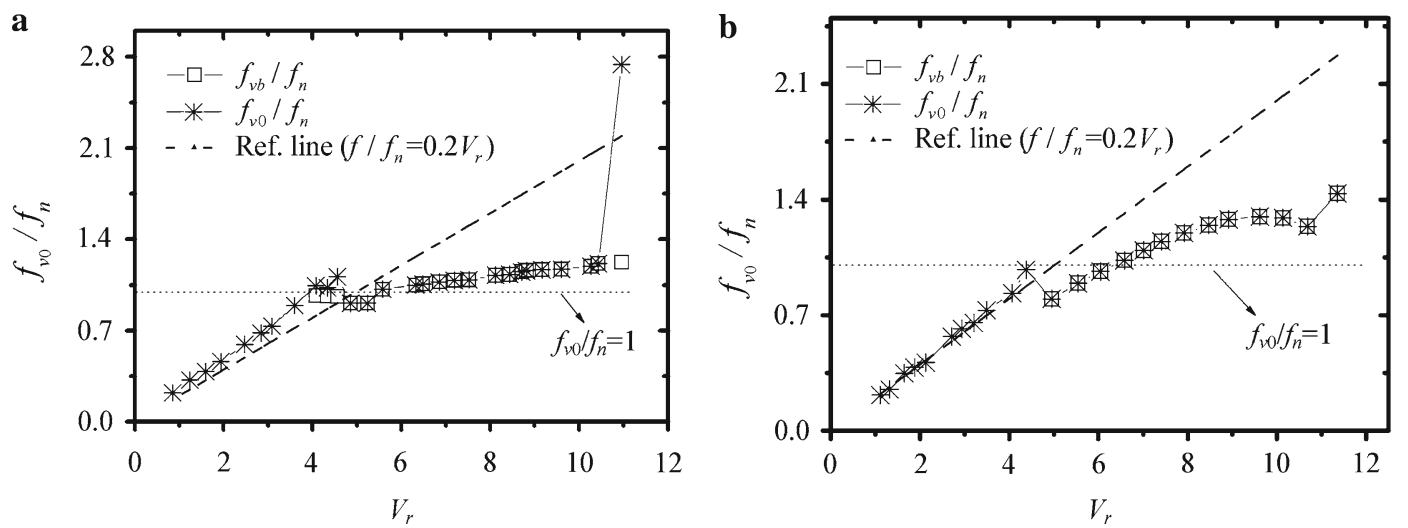

Fig. 9 The variation of frequency of wake vortices shed from the cylinder undergoing vortex-induced vibration versus $V_{r}$ number. a $e_{0} / D=1.00$, $m^{*}=3.87, K_{s}=0.0741 ; \mathbf{b} e_{0} / D=1.50, m^{*}=2.32, K_{s}=0.1870$
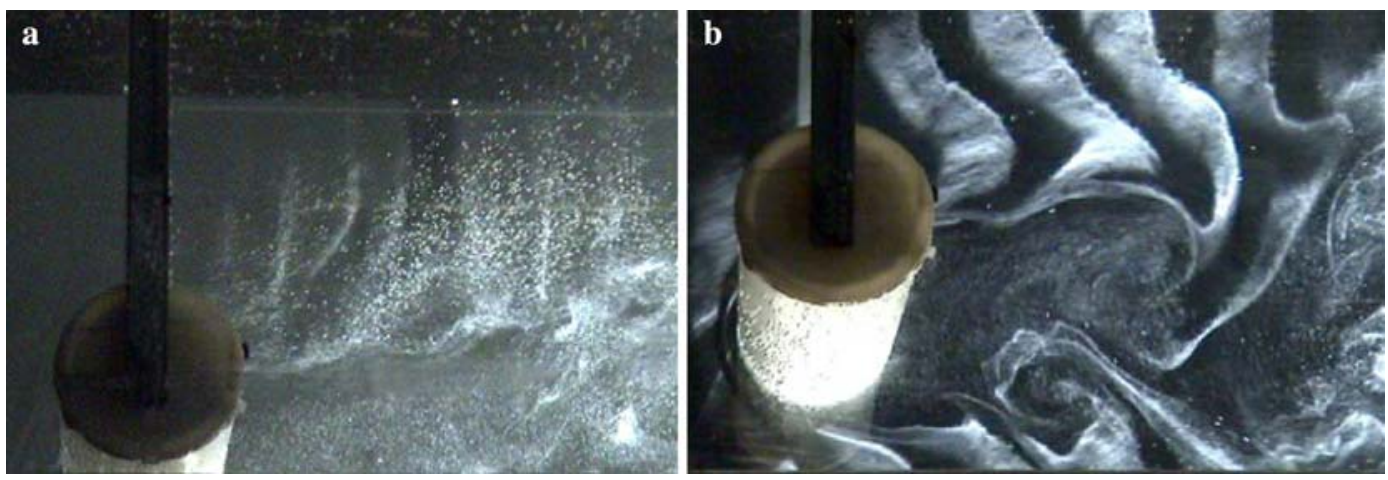

Fig. 10 Flow visualization of wake flow of a static cylinder (Hydrogen bubble). a $e_{0} / D=0.20, R e=2.5 \times 10^{3} ; \mathbf{b} e_{0} / D=1.00, R e=2.5 \times 10^{3}$

reported by Tsahalis and Jones [31] and Fredsoe et al. [34]. It is observed in Fig. 12b that the influences of gap-to-diameter ratios on the vibration frequency are noticeable for the small gap-to-diameter ratio cases. The absolute values of dimensionless vibration frequency for the smaller gap-to-diameter ratios (e.g., $\left.e_{0} / D=0.06,0.30\right)$ are much larger than those for the larger ones (e.g., $e_{0} / D=0.66,0.88$ ) at the same $V_{r}$ number.

\subsubsection{Effect of the stability parameter $\left(K_{S}\right)$}

The stability parameter $\left(K_{S}\right)$ indicates the ability of the cylinder to dissipate energy. In general, when other parameters are fixed, the larger the stability parameter is, the more energy will be dissipated in the same time. Figure 13 illustrates the response of the cylinder with different stability parameters. It can be seen from Fig. 13a that the maximum amplitudes are $0.48 D$ for $K_{s}=0.3209$ and $0.67 D$ for $K_{s}=0.0741$. The range of vibration in terms of $V_{r}$ number are $5<V_{r}<6.5$ for $K_{s}=0.3209$ and $3.2<V_{r}<8.3$ for $K_{s}=0.0741$. That is, when other parameters are fixed, with the increase of stability parameter the maximum amplitude and the range of vibration have smaller values. However, for the response of the frequency, it is different from the amplitude response. The effects of the stability parameter upon the dimensionless frequency $f / f_{n}$ are very weak, as indicated in Fig. 13b. Therefore, the stability parameter mainly affects the maximum amplitude of the vibration and the range of vibration in terms of $V_{r}$ number.

\subsubsection{Effect of mass ratio $\left(m^{*}\right)$}

The dimensionless parameter $m *$ indicates the ratio of the mass of the cylinder per unit and the mass of the water whose volume is occupied by the cylinder per unit, i.e., the ratio of the cylinder inertia and the fluid inertia. There is a larger inertia for the cylinder with a larger mass ratio. Figure 14 shows the effects of the mass ratio upon the dynamic response of the cylinder. It is indicated from Fig. 14 that the mass ratio has an influence upon the vibration range of the cylinder. The smaller mass ratio corresponds to the larger vibration range of the cylinder. Moreover, it is observed from Fig. 14b that the mass ratio also affects the variation of the vibration frequency of the cylinder. The frequency ratio $\left(f / f_{n}\right)$ for the smaller mass ratio is much larger than that for the larger one at the same $V_{r}$ number. 
Fig. 11 Flow visualization of wake flow of a cylinder undergoing vortex-induced vibration (Hydrogen bubble) $\left(A / D=0.18, V_{r}=3.6, T\right.$ : vibration period of the cylinder). a $t=0.25 T$ (at the top); b $t=0.5 T$; $\mathbf{c} t=0.75 T$ (at the bottom); $\mathbf{d} t=1 T$

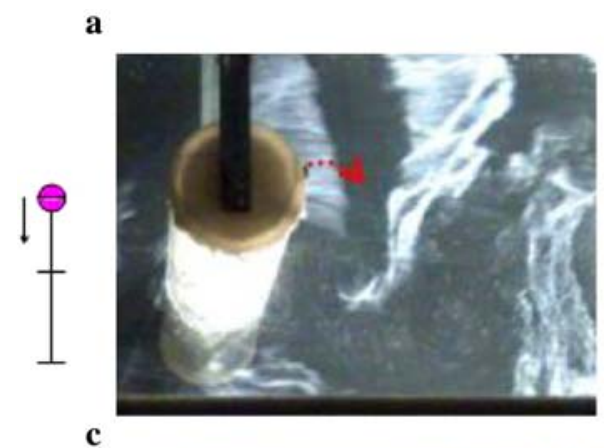

b
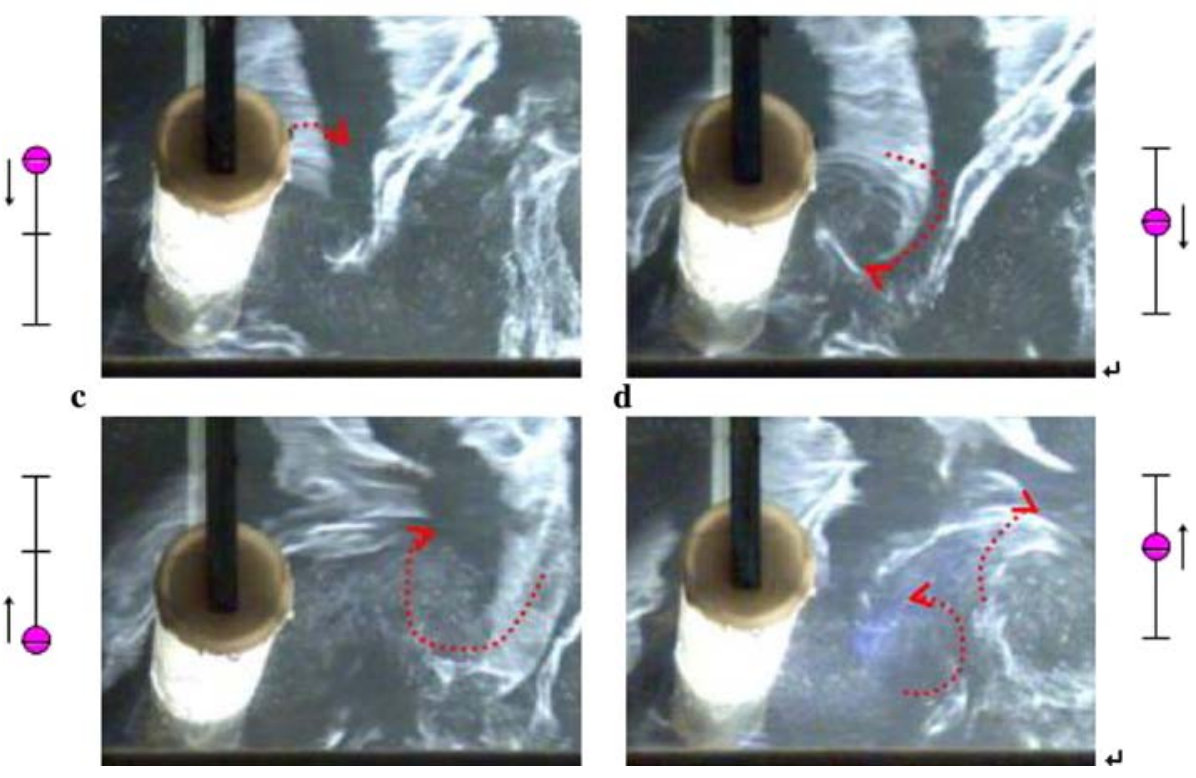

a

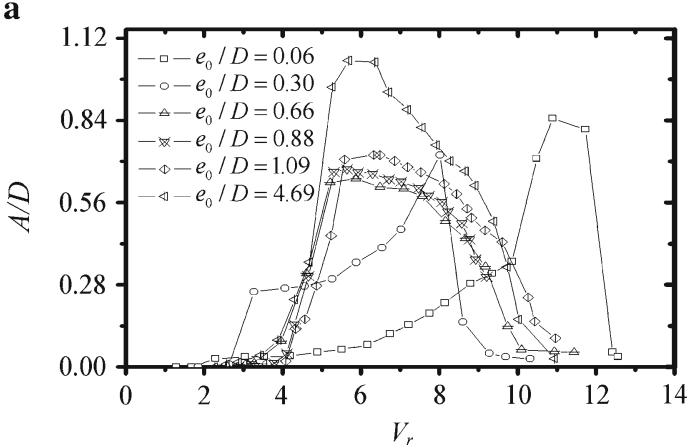

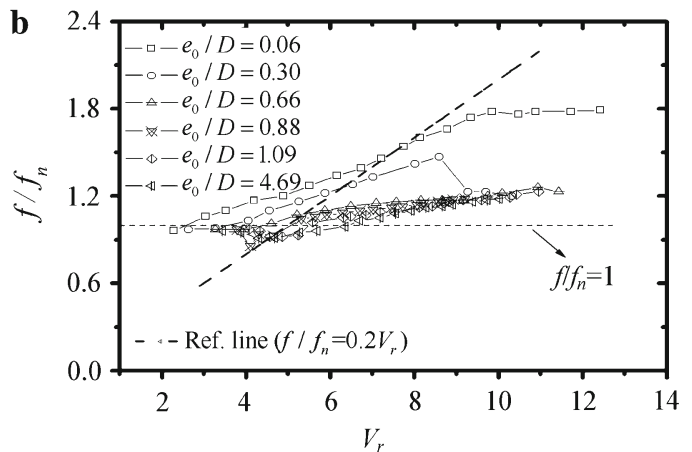

Fig. 12 Response of vibration amplitude and frequency of the cylinder with different gap-to-diameter ratios $\left(D=0.032 \mathrm{~m}, m^{*}=3.87\right.$, $K_{s}=0.0741$ ). a Amplitude response; $\mathbf{b}$ frequency response
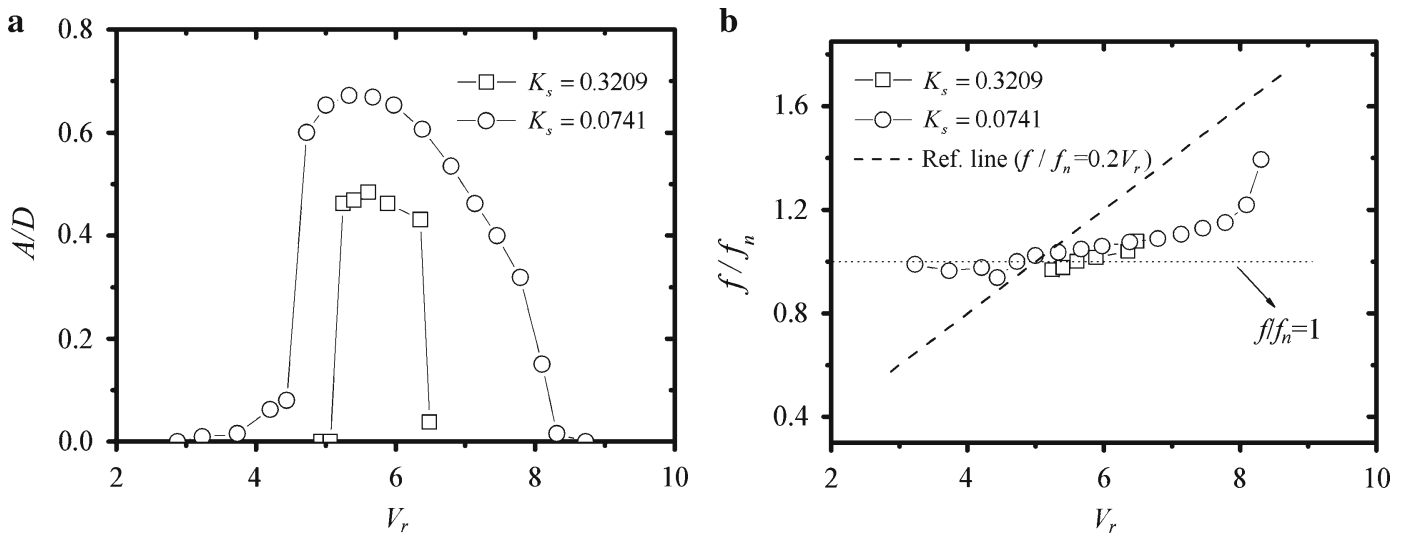

Fig. 13 Response of vibration amplitude and frequency of the cylinder with different stability parameters $\left(D=0.032 \mathrm{~m}, m^{*}=3.87, e_{0} / D=0.66\right)$. a Amplitude response; b Frequency response 

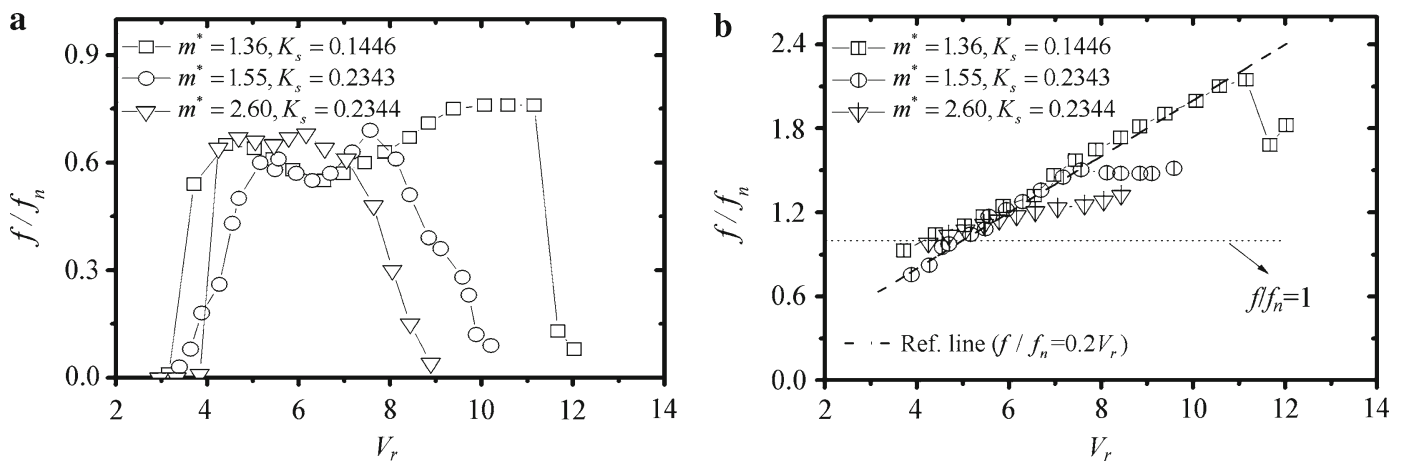

Fig. 14 Response of vibration amplitude and frequency of the cylinder with different mass ratios $\left(D=0.05 \mathrm{~m}, e_{0} / D=1.00\right)$. a Amplitude response; $\mathbf{b}$ frequency response
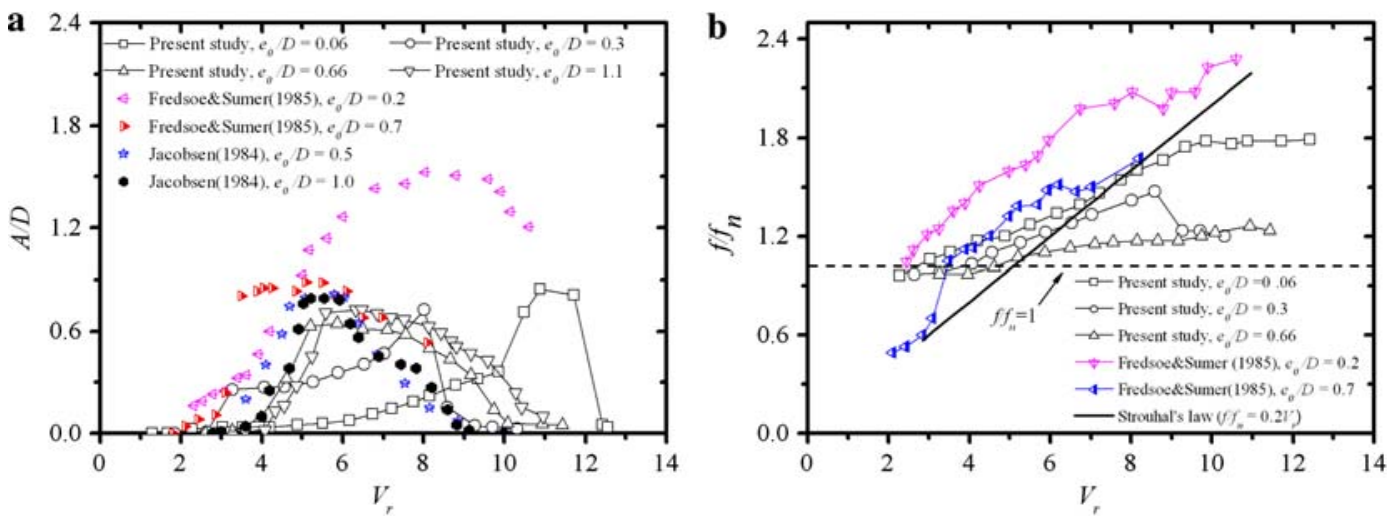

Fig. 15 Comparison of present results with previous studies. a Amplitude response; $\mathbf{b}$ frequency response

\subsection{Comparison of present results with previous study}

A comparison between the previous works, including those by Jacobsen et al. [33] and Fredsoe and Sumer [34], and the present results is plotted in Fig. 15. In the work by Jacobsen et al. [33], the mass ration $\left(m^{*}\right)$ according to present definition in this study is 2.51 , the stability parameter $\left(K_{S}\right)$ is larger than the value of 0.5968 . It is noted that the vibration amplitude employed by Jacobsen et al. [33] is the maximal amplitude, and those by present study and Fredsoe and Sumer [34] are average ones. In the study of Fredsoe and Sumer [34], the mass ratio is not described directly, but the relative density of the cylinder is presented. Therefore, the mass ratio can be deduced according to relative density of the cylinder, i.e., $m^{*}=1$. It can be seen from Fig. 15a that the variation of $A / D$ with reduced velocity $\left(V_{r}\right)$ for the case of $e_{0} / D=0.66,1.1$ in present study has a similar trend with that for the case of $e_{0} / D=0.5,1.0,0.7$ in the work by Jacobsen et al. [33] and Fredsoe and Sumer [34]. That is to say, for the case of larger gap-to-diameter ratio the amplitude response of the cylinder in present study is similar to those by Jacobsen et al. [33] and Fredsoe and Sumer [34]. But for the smaller gap-to-diameter ratio case, there is some differences between present results and those by Fredsoe and Sumer [34]. The maximum of vibration amplitude in the work by Fredsoe and Sumer [34] for $e_{0} / D=0.2$ case is much larger than those in this study for $e_{0} / D=0.06$ and 0.3 . In addition, the trend of variation of vibrating amplitude with reduced velocity has also some differences between them, as indicated from Fig. 15a.

It is observed from the vibrating frequency response in the Fig. 15b that the influence of gap-to-diameter ratio upon dimensionless vibrating frequency of the cylinder shows the same variation trend in the work by Fredsoe and Sumer [34] and present study, i.e., the dimensionless vibrating frequency of the cylinder increases with the decrease of gap-to-diameter ratio within some ranges of gap-to-diameter ratio under condition of the fixed values of other parameters. The difference is that the dimensionless vibrating frequency of the cylinder reported by Fredsoe and Sumer [34] is larger than that in present study at the same value of $V_{r}$. It can be seen that the dimensionless vibration frequency in the work with $e_{0} / D=0.7$ by Fredsoe and Sumer [34] is even larger than that in present study with $e_{0} / D=0.06$.

\section{Concluding remarks}

The experiments on VIV of the cylinder near a rigid plane boundary are conducted in a flume. The typical characteristic 
of the phenomenon on the close-wall VIV of the cylinder is presented. The vortex shedding frequency in the wake flow of the cylinder is analyzed by hot film veloci-meters. The flow visualization around the cylinder is performed with the hydrogen bubble method. Based on experimental results, the following conclusions can be drawn:

During vibrations, the dimensionless vibration amplitude of the cylinder $(A / D)$ undergoes the process of increasingmaximum-decreasing variation with increasing $V_{r}$ number, while the dimensionless vibration frequency $\left(f / f_{n}\right)$ increases slowly with the increase of $V_{r}$ number.

The Strouhal number $(S t)$ is around 0.2 for the cylinder near a plane boundary in the sub-critical flow regime. The vortex shedding mode from the cylinder undergoing VIV at the initial stage of vibration (usually at small $V_{r}$ number) is $2 \mathrm{~S}$ mode.

With increasing gap-to-diameter ratio $\left(e_{0} / D\right)$, the amplitude ratio $(A / D)$ gets larger and frequency ratio $\left(f / f_{n}\right)$ has slight variation for the case of larger values of $e_{0} / D\left(e_{0} / D>\right.$ 0.66 in this study). The frequency ratio for the case of smaller values of $e_{0} / D\left(e_{0} / D<0.3\right.$ in this study $)$ is much larger than that for the case of larger ones at same $V_{r}$ number.

The vibration of the cylinder is easer to occur and its amplitude response becomes more extensive with the decrease of the stability parameter, but the frequency response is affected weakly by the stability parameter. With decreasing mass ratio, the width of the lock-in ranges in terms of $V_{r}$ and the frequency ratio $\left(f / f_{n}\right)$ become larger.

Acknowledgments The helpful discussions with Professor Zhichu Zheng and Professor Zhonghan Shen, and the technical support in the experiments from Donghui Li and Shuming Yan are also greatly appreciated.

\section{References}

1. Drescher, H.: Messung der auf querangestromte zylinder ausgeubten zeitlich veranderten. Drucke Z.F. Flugwiss 4(112), 17-21 (1956)

2. Sarpkaya, T.: Vortex-induced oscillations-a selective review. J. Appl. Mech. Trans. ASME 46, 241-258 (1979)

3. Sarpkaya, T.: A critical review of the intrinsic nature of vortexinduced vibrations. J. Fluid Struct. 19, 389-447 (2004)

4. Griffin, O.M., Ramberg, S.E.: Some recent studies of vortex shedding with application to marine tubulars and risers. J. Energy Resour. Technol. ASME 104, 2-13 (1982)

5. Bearman, P.W.: Vortex shedding from oscillating bluff bodies. Annu. Rev. Fluid Mech. 16, 195-222 (1984)

6. Parkinson, G.: Phenomena and modeling of flow-induced vibrations of bluff bodies. Progress Aerospace Sci. 26, 169-224 (1989)

7. Sumer, B.M., Fredsoe, J.: A review on vibrations of marine pipelines. Int. J. Offshore Polar Eng. 5(2), 81-90 (1995)

8. Sumer, B.M., Fredsoe, J.: Hydrodynamics around Cylindrical Structures. World Scientific, Singapore, p 527 (1997)

9. Williamson, C.H.K., Govardhan, R.: Vortex-induced vibrations. Annu. Rev. Fluid Mech. 36, 413-455 (2004)
10. Feng, C.C.: The measurement of vortex-induced effects on flow past stationary and oscillating circular and D-section cylinders. MSc Thesis, The University of British Columbia, Canada (1968)

11. Anand, N.M.: Free span vibrations of submarine pipelines in steady and wave flows. Doctoral Thesis, Div. of Port and Ocean Engineering. Trondheim: The Univ. of Trondheim, The Norwegian Institue of Technology (1985)

12. Brika, D., Laneville, A.: Vortex-induced vibrations of a long flexible circular cylinder. J. Fluid Mech. 250, 481-508 (1993)

13. Khalak, A., Williamson, C.H.K.: Dynamics of a hydroelastic cylinder with very low mass and damping. J. Fluids Struct. 10, 455472 (1996)

14. Khalak, A., Williamson, C.H.K.: Investigation of the relative effects of mass and damping in vortex-induced vibration of a circular cylinder. J. Wind Eng. Ind. Aerodyn. 69(71), 341-350 (1997)

15. Khalak, A., Williamson, C.H.K.: Fluid forces and dynamics of a hydroelastic structure with very low mass and damping. J. Fluids Struct. 11, 973-982 (1997b)

16. Govardhan, R., Williamson, C.H.K.: Modes of vortex formation and frequency response for a freely-vibrating cylinder. J. Fluid Mech. 420, 85-130 (2000)

17. Khalak, A., Williamson, C.H.K.: Motions, forces and mode transitions in vortex-induced vibrations at low mass-damping. J. Fluids Struct. 13, 813-851 (1999)

18. Williamson, C.H.K., Roshko, A.: Vortex formation in the wake of an oscillating cylinder. J. Fluids Struct. 2, 355-381 (1988)

19. Vickery, B.J., Watkins, R.D.: Flow-induced vibrations of cylindrical structures. In: Proceedings of the First Australian Conference on Hydraulics and Fluid Mechanics. Pergamon Press, New York (1964)

20. Scruton, C.: On the wind-excited oscillations of towers, stacks and masts. In: Proceedings of the Symposium on Wind Effects on Buildings and Structures. Her Majesty's Statio Nery Office, Paper 16, London, pp 798-836 (1965)

21. Skop, R.A., Griffin, O.M.: A model for the vortex-induced oscillation of structures. ASME J. Appl. Mech. 41, 581-586 (1973)

22. Skop, R.A., Balasubramanian, S.: A new twist on an old model for vortex-excited vibrations. J. Fluids Struct. 11, 395-412 (1997)

23. Sarpkaya, T.: Fluid forces on oscillating cylinders. ASCE J. Waterway Port Coastal Ocean Divis. 104, 275-290 (1978)

24. Sarpkaya, T.: Hydrodynamic damping, flow-induced oscillations, and biharmonic response. ASME. J. Offshore Mech. Arctic Eng. 117, 232-238 (1995)

25. Zdravkovich, M.M.: On origins of hysteretic responses of a circular cylinder induced by vortex shedding. Zeitschrift Flugwissenschaften Weltraumforschung 14, 47-58 (1990)

26. Bearman, P.W., Zdravkovich, M.M.: Flow around a circular cylinder near a plane boundary. J. Fluid Mech. 109, 33-48 (1978)

27. Grass, A.J., Raven, P.W.J., Stuart, R.J., Bray, J.A.: The influence of boundary layer velocity gradients and bed proximity on vortex shedding from free spanning pipelines. J. Energy Resour. Technol. Trans. ASME 106, 70-78 (1984)

28. Taniguchi, S., Miyakoshi, K.: Fluctuating fluid forces acting on a circular cylinder and interference with a plane wall. Exp. Fluids 9, 197-204 (1990)

29. Buresti, G., Lanciotti, A.: Mean and fluctuating forces on a circular cylinder in cross-flow near a plane surface. J. Wind Eng. Ind. Aerodyn. 41, 639-650 (1992)

30. Lei, C., Cheng, L., Kavanagh, K.: Re-examination of the effect of a plane boundary on forces and vortex shedding of a circular. J. Wind Eng. Ind. Aerodyn. 80(3), 263-286 (1999)

31. Tsahalis, D.T., Jones, W.T.: Vortex-induced vibration of a flexible cylinder near a plane boundary in steady flow. In: Offshore Technology Conferences, Houston, vol. 3991, pp 367-386 (1981) 
32. Tsahalis, D.T.: Vortex-induced vibrations of a flexible cylinder near a plane boundary exposed to steady and wave-induced currents. J. Energy Resour. Technol. Trans. ASME 106, 206-213 (1984)

33. Jacobsen, V., Bryndum, M.B., Nielsen, R., Fines, S.: Cross-flow vibration of a pipe close to a rigid boundary. J. Energy Resour. Technol. Trans. ASME 106, 451-457 (1984)

34. Fredsoe, J., Sumer, B.M., Andersen, J., Hansen, E.A.: Transverse vibration of a cylinder very close to a plane wall. In: Proceeding of the 4th International Symposium on Offshore Mechanics and Arctic Engineering, ASME, Dallas, vol. 1, pp 601-609 (1985)

35. Gao, F.P., Yang, B., Wu, Y.X., Yan, S.M.: Steady current induced seabed scour around a vibrating pipeline. Appl. Ocean Res. 28, 291-298 (2006)
36. Raven, P.W.J., Stuart, R.J.: Full-scale dynamic testing of submarine pipeline spans. In: Offshore Technology Conferences, Houston, vol. 5005, pp 395-404 (1985)

37. Achenbach, E., Heinecke, E.: On vortex shedding from smooth and rough cylinders in the range of Reynolds numbers $6 \times 10^{3}$ to $5 \times 10^{6}$. J. Fluid Mech. 109, 239-251 (1981)

38. King, R., Prosser, M.J., Johns, D.J.: On vortex excitation of model piles in water. J. Sound Vib. 29(2), 169-188 (1973) 